\title{
Impacto clínico de la influenza A H1N1 pandémica en el hospital de Puerto Montt, Chile
}

\author{
RAÚL RIQUELME O. ${ }^{1}$, MAURICIO RIQUELME O. ${ }^{1}$, \\ MARÍA LUISA RIOSECO Z. ${ }^{2}$, CARLOS INZUNZA P. ${ }^{1}$, CRISTIAN CONTRERAS \\ G. ${ }^{a}$, YARELLA GÓMEZ V. ${ }^{\text {a }}$ JAVIER RIQUELME D. ${ }^{\mathrm{a}}$
}

\section{Clinical impact of pandemic influenza A H1N1 in a Chilean regional hospital}

Background: Pandemic flu (H1N1) strongly affected southern Chile during 2009. Aim: To report the logistic and organizational changes implemented at a regional hospital to face the pandemic. Material and Methods: All patients with flu like disease that were hospitalized, were prospectively enrolled at the Puerto Montt hospital. A nasopharyngeal aspirate was obtained in all for influenza virus $A$ and B direct immunofluorescence and polymerase chain reaction (PCR). All epidemiological and clinical data of patients were recorded. Results: Between May 29 and July 7, 2009, 184 adults were admitted to the hospital and in 117 patients aged $41 \pm 18$ years (56\% females), direct immunofluorescence was positive for influenza. In 67 of these patients PCR did not confirm the disease. These unconfirmed patients had a mean age of 49 \pm 19 years ( $p<0.01$, compared with confirmed cases) and had a lower frequency of fever, rhinorrhea and chills. No significant differences in the incidence of community acquired pneumonia or chest $X$ ray findings were observed between confirmed and unconfirmed cases. Hospital stay was over 15 days in $14 \%$ of confirmed cases and $5 \%$ of unconfirmed cases ( $p=0.03$ ). Fifteen patients, aged $53 \pm 18$ years, died. Conclusions: Low sensibility of direct immunofluorescence and delay in obtaining PCR confirmation of influenza posed a problem for the management of these patients.

(Rev Med Chile 2011; 139: 321-326).

Key words: Fluorescent antibody technique; H1N1 virus; Influenza, human.

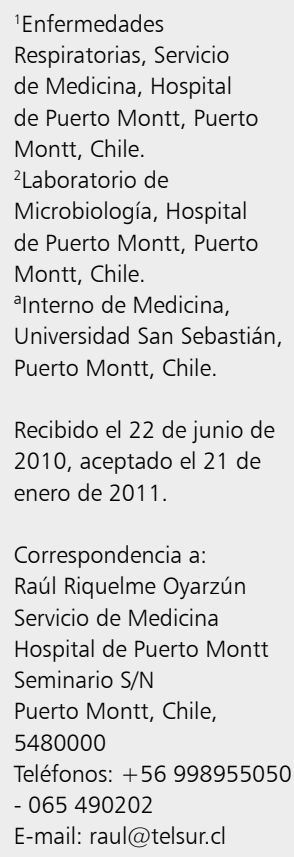

$\mathrm{E}$ n abril de 2009, el Centers for Disease Control (CDC) de los Estados Unidos de Norteamérica identificó un nuevo virus de influenza A H1N1 de origen porcino (IA H1N1pdm) y en forma coincidente, fue detectado en pacientes con cuadros respiratorios en México ${ }^{1}$. El virus se extendió rápidamente y en julio de ese año, la OMS declaró que su propagación había alcanzado el nivel de pandemia ${ }^{2}$.

El 17 de mayo se confirmaron los primeros casos en Chile y el 24 de mayo, el caso índice en Puerto Montt, al sur de Chile. El 2 de junio falleció en el hospital de esta ciudad el primer paciente en Chile y América del Sur a causa de una infección por IA H1N1pdm. De inmediato fue evidente el impacto local de la pandemia ya que una semana después, cuando Chile reportaba 500 casos confirmados, 7 graves y 2 fallecidos, 6 graves y ambos fallecidos pertenecían a la X Región. Al 20 de julio, Chile había confirmado 11.293 casos y 68 fallecidos $(0,6 \%)$.

La X Región (825.000 habitantes) tiene como capital la ciudad de Puerto Montt (230.855 habitantes) situada a $41^{\circ} 30^{\prime}$ de latitud sur y $72^{\circ} 50^{\prime} \mathrm{de}$ longitud oeste. Su clima es lluvioso y frío, con temperaturas entre $0^{\circ} \mathrm{C}$ y $8{ }^{\circ} \mathrm{C}$ en el período del estudio. Su aeropuerto es el segundo en importancia 
del país, con un fuerte intercambio internacional por la industria salmonera y el turismo.

El Hospital Base de Puerto Montt (HBPM), hospital general de 440 camas, es el principal de la X Región. A consecuencia de la pandemia, debió enfrentar un aumento de ingresos por cuadros respiratorios agudos que obligaron a modificar progresivamente su funcionamiento, implementando estrategias de hospitalización variables de acuerdo a la demanda, destinadas a prevenir la transmisión nosocomial del virus y asegurar los cuidados clínicos que cada caso ameritaba según su presentación y evolución.

Este trabajo tiene como propósitos describir las modificaciones organizacionales y logísticas implementadas en el HBPM para el manejo de adultos hospitalizados durante el brote de IA H1N1pdm y describir las diferencias encontradas entre casos confirmados y no confirmados como IA H1N1pdm.

\section{Material y Método}

Se registraron prospectivamente todos los casos de adultos con enfermedad tipo influenza (ETI) que ingresaron al HBPM entre el 29 de mayo y el 7 julio 2009. Se utilizó la definición de ETI del Ministerio de Salud: temperatura axilar $\geq 38,5^{\circ} \mathrm{C}$, tos y otro síntoma como mialgias, odinofagia o cefalea. A cada paciente se le tomó aspirado nasofaríngeo para inmunofluorescencia directa (IFD) de virus influenza A y B y se envió una muestra al Instituto de Salud Pública (ISP) para detección de IA H1N1pdm mediante reacción de polimerasa en cadena en tiempo real (RT-PCR).

Se consignaron antecedentes epidemiológicos, clínicos y radiológicos. Se consideró que un paciente tenía una neumonía adquirida en la comunidad (NAC) si cumplía con los criterios de Fang et $\mathrm{al}^{3}$. Cuando hubo NAC se evaluó si al ingreso cumplía con los criterios IDSA/ATS para admisión en Unidad de Cuidados Intensivos $(\mathrm{UCI})^{4}$. Se registraron las descompensaciones de comorbilidades, presencia de síndrome de distress respiratorio del adulto (SDRA), shock, insuficiencia renal aguda, necesidad de UCI, ventilación mecánica (VM), estadía hospitalaria y mortalidad.

Se registró el antiviral utilizado, uso y modificación de antibióticos durante la evolución. Se consideró mortalidad atribuible a NAC si no había otra causa que la explicara.
Consideramos caso confirmado todo paciente con ETI y RT- PCR $(+)$ y caso no confirmado todo paciente con ETI y RT- PCR (-). Los casos con IFD (+) para IA en los que no obtuvimos resultado de PCR, fueron considerados confirmados, pues en ese momento $99 \%$ de las cepas correspondían a H1N1pdm. Los casos con IFD (+) y PCR (-), en que se descartó influenza estacional, fueron considerados falsos (+) e incluidos en los no confirmados. Se comparó el comportamiento clínico de ambos grupos.

Para la descripción de las modificaciones organizacionales en el hospital, se revisaron registros de reuniones entre el equipo directivo, médicos y Comité de Infecciones Intrahospitalarias realizadas durante el período. Se obtuvo información de documentos difundidos por la dirección, donde se especificaban las modificaciones de funcionamiento por el aumento de demanda asistencial. Los autores además, formaron parte del grupo encargado de analizar la epidemiología nacional y local para apoyar al equipo directivo en la toma de decisiones.

Análisis Estadístico: Los resultados son expresados como valores promedio con desviación estándar. Para comparación de variables continuas se empleó $t$ de Student y el test de $\chi^{2}$ o test exacto de Fisher cuando fue apropiado para las variables categóricas. Un valor bilateral de $\mathrm{p}<0,05$ se consideró significativo.

\section{Resultados}

Durante el período de estudio fueron hospitalizados 184 adultos con ETI.

Se planificó que todo paciente ingresaría a sala individual y se establecieron cohortes para los casos confirmados. Para ello, el Servicio de Medicina (66 camas) habilitó 8 piezas individuales como aislamiento y el Servicio de Pensionado, 12 adicionales. En ambos servicios se recibieron pacientes desde Urgencia con ETI en espera de confirmación mediante IFD y/o RT-PCR. Una Unidad de Intermedio de 6 camas se utilizó para cohorte de casos con IFD (+) y PCR (+). La UCI se transformó progresivamente en lugar de tratamiento en cohorte para los más graves, utilizando el máximo de su capacidad. Se suspendieron las cirugías electivas y se usaron camas de cirugía para pacientes de medicina con otras patologías. 
Todos los casos eran evolucionados diariamente por internistas o médicos generales. Especialistas en enfermedades respiratorias realizaban una evaluación diaria para ajustar tratamientos, decidir el lugar de hospitalización y el alta. Por la demanda de camas, se buscaba un alta precoz con control asegurado en el Policlínico de Broncopulmonar a las 24 a 48 horas.

Los ingresos a las diferentes unidades fueron decididos considerando criterios clínicos, radiológicos, de gravedad y resultados de IFD, disponibles en el día. De preferencia, todo caso nuevo ingresaba a un aislamiento individual, pero la creciente demanda determinó que en corto plazo, esto no fuera posible. Frecuentemente hubo demora en el diagnóstico definitivo ya que la muestra debía enviarse a Santiago. Esto obligó a habilitar en Medicina dos salas adicionales de 4 camas para cohorte de aquellos con sospecha clínica menor y con IFD (-), en espera de confirmación. Se definió como bajo índice de sospecha a mayores de 60 años, con leucocitosis y síntomas menos evidentes de ETI.

El 63,6\% (117/184) correspondió a casos confirmados y de ellos, 17 no tuvieron resultado de PCR pese a haber enviado la muestra al ISP. Las características clínicas de 100 de estos casos fueron publicadas $^{5}$. El 49\% de los casos con RT-PCR (+) tuvo IFD negativa. Dos pacientes con IFD $(+)$ para IA y RT-PCR (-) fueron incluidos en el grupo de no confirmados.

La edad fue de $41 \pm 18$ (15-79) años para los confirmados y de 48,5 \pm 19 (15-87) para los no confirmados $(\mathrm{p}=0,01)$.

Los hallazgos encontrados al comparar ambos grupos se resumen en la Tabla 1. No hubo diferencias en la frecuencia de diabetes, cardiopatía,

Tabla 1. Comparación de adultos con IA H1N1pdm confirmados y aquellos con ETI sin confirmación

\begin{tabular}{|c|c|c|c|c|}
\hline & $\begin{array}{c}\text { Confirmados } \\
n=117(\%)\end{array}$ & $\begin{array}{c}\text { No confirmados } \\
n=67(\%)\end{array}$ & $\mathbf{p}$ & OR IC $95 \%$ \\
\hline Edad \pm DS & $41 \pm 18$ & $48,5 \pm 19$ & 0,010 & \\
\hline Sexo femenino & $65(55,6)$ & $38(56,7)$ & 0,501 & \\
\hline Edad $\geq 65$ años & $15(12,8)$ & $14(20,9)$ & 0,109 & \\
\hline Días de hospitalización \pm DS & $7,9 \pm 8,2$ & $5,7 \pm 4,6$ & 0,056 & \\
\hline Hospitalización $\geq 15$ días & $16(13,9)$ & $3(4,5)$ & 0,035 & \\
\hline Embarazo & 7 (6) & $1(1,5)$ & 0,261 & \\
\hline Enfermedad pulmonar crónica & $31(26,5)$ & $8(11,9)$ & 0,024 & $2,6 \quad(1,1-6,1)$ \\
\hline Fiebre al ingreso & $112(95,7)$ & $50(75,8)$ & 0,000 & $7,1(2,4-20,5)$ \\
\hline Cefalea & $69(59,1)$ & $47(40,9)$ & 0,000 & $3,3 \quad(1,7-6,3)$ \\
\hline Coriza & $39(33,6)$ & $9(13,6)$ & 0,005 & $3,1 \quad(1,4-6,9)$ \\
\hline Mialgias & $84(73)$ & $38(57,6)$ & 0,047 & $2(1,0-3,8)$ \\
\hline Escalofríos & $56(47,8)$ & $6(9,1)$ & 0,000 & $9,3(3,7-23,3)$ \\
\hline Odinofagia & $39(33,9)$ & $14(21,2)$ & 0,090 & \\
\hline Diarrea & $14(12,2)$ & $2(3,0)$ & 0,054 & \\
\hline Recuento leucocitos $\pm \mathrm{DE}$ & $9.840 \pm 5.739$ & $14.705 \pm 8.026$ & 0,000 & \\
\hline Recuento leucocitos $>20.000$ & $9(8)$ & $13(20)$ & 0,032 & \\
\hline Recuento leucocitos $<10.000$ & $70(62,5)$ & $20(30,8)$ & 0,000 & \\
\hline Neumonía comunitaria & $85(73,3)$ & $40(61,5)$ & 0,131 & \\
\hline SDRA al ingreso & $8(8,5)$ & 0 & 0,023 & \\
\hline $\mathrm{UCl}$ & $24(20,7)$ & $2(3,0)$ & 0,001 & $8,5(1,9-37,1)$ \\
\hline VM & $17(14,7)$ & $1(1,5)$ & 0,004 & $10,9(1,4-84,6)$ \\
\hline Mortalidad & $10(8,5)$ & $5(7,5)$ & 1,000 & \\
\hline
\end{tabular}


insuficiencia renal crónica, obesidad, enfermedad neurológica, alcoholismo y enfermedad hepática crónica. Sin embargo, en los confirmados fue más frecuente el asma o EPOC $(\mathrm{p}=0,024)$. Hubo 8 embarazadas, confirmándose IA H1N1pdm en 7.

En los no confirmados hubo menor frecuencia de fiebre, cefalea, coriza y calosfríos. La NAC fue más frecuente en el grupo confirmado sin ser significativo.

La radiología no mostró diferencias en el tipo de infiltrado, lóbulos comprometidos o bilateralidad. La progresión rápida de infiltrados fue más frecuente en los pacientes confirmados, sin ser significativo $(14,8 \%$ vs $2,5 \%, p=0,063)$. Hubo SDRA al ingreso en 8 de los confirmados y en ninguno de los no confirmados $(p=0,023)$.

El recuento de leucocitos fue menor en los casos confirmados $(\mathrm{p}=0,000)$.

Los pacientes confirmados ingresaron en mayor número a UCI y requirieron con mayor frecuencia VM. No hubo diferencia en la presencia de shock. La hospitalización fue $>15$ días en $13,9 \%$ de los confirmados y en $4,5 \%$ de los no confirmados $(\mathrm{p}=0,035)$.

Todos recibieron tratamiento antiviral con oseltamivir, salvo 7 de las 8 embarazadas que recibieron zanamivir. El 85\% recibió antibióticos, principalmente ceftriaxona (40\%) o asociada a macrólido o quinolona (40\%), sin diferencias en ambos grupos. El esquema fue modificado por especialista en las primeras 24 horas en $25 \%$ (47/184), generalmente simplificándolo.

Fallecieron 15 pacientes, todos con neumonía, sin diferencias en ambos grupos. La edad promedio de los fallecidos fue de 52,9 $\pm 17,5$ (18-77), cuatro tenían más de 65 años y sólo uno de ellos IApdm confirmada. Fueron trasladados vía aérea a Santiago 3 pacientes para ECMO y uno a Concepción para diálisis. Todos fallecieron.

\section{Discusión}

Nuestro trabajo describe la difícil situación sanitaria vivida durante la pandemia por IA H1N1pdm en un hospital del sur de Chile que en 40 días debió hospitalizar a 184 adultos con ETI. La baja sensibilidad de la IFD y la demora en obtener la confirmación por RT-PCR fueron importantes dificultades para implementar medidas de prevención de infecciones intrahospitalarias. En forma paralela a aquellos pacientes con IA H1N1pdm demostrada, se hospitalizaron pacientes en los que se debió usar aislamiento pero que fueron RT-PCR (-) y que tuvieron un comportamiento clínico diferente.

El servicio de urgencia del HBPM debió enfrentar un aumento de consultas por ETI y la decisión de hospitalización fue tomada en base a criterios clínicos. Rápidamente fue evidente, dado el incremento de la población consultante, que el diagnóstico mediante IFD y/o RT-PCR no eran de mayor valor para decidir la hospitalización pero eran fundamentales para decidir donde hospitalizar. Sin embargo, la IFD demostró una sensibilidad de $51 \%{ }^{5}$ por lo que el grupo con IFD (-) representó el mayor problema para implementar medidas de prevención de transmisión nosocomial. La sobrecarga del ISP determinó que algunas muestras no fueran procesadas, hubiera retraso en la obtención de resultados y en ocasiones, que estuvieran disponibles cuando carecían de importancia clínica o epidemiológica. Este dilema diagnóstico y la discordancia de los test de influenza han sido descritos $^{6}$ e intentamos resolverlos empleando criterios clínicos. Los criterios para presumir una menor probabilidad de IA H1N1pdm fueron: mayores de 60 años, leucocitosis importante y síntomas de ETI menos sugerentes. El análisis posterior demostró que estos factores eran significativamente distintos en los no confirmados, pero individualmente fueron causa de que pacientes RT-PCR (-) estuvieran en contacto con pacientes confirmados. Sin embargo, todos recibieron terapia antiviral y no hubo transmisión nosocomial.

Si bien ambos grupos cumplían con la definición de ETI, hubo diferencias que deben ser comentadas. En el grupo IA H1N1pdm los síntomas fueron aquellos clásicamente descritos para influenza (fiebre, tos, mialgias, cefalea, coriza) mientras que los no confirmados presentaron un cuadro oligosintomático. Esto podría explicarse en parte porque enfrentados a una pandemia y bajo fuerte exposición a los medios de comunicación, como ocurrió, los criterios para hospitalizar pudieron ser más permisivos o menos estrictos. Sin desconocer lo anterior, es conocido que la influenza tiene diferentes presentaciones, la fiebre algunas veces es baja y cardiopatías o condiciones pulmonares previas pueden confundir el diagnóstico ${ }^{7}$. En ancianos, el cuadro clínico puede estar modificado y la triada fiebre, tos, e inicio súbito 
tiene un valor predictivo de sólo $30 \%$, mientras en el adulto joven llega a $78 \%{ }^{8}$.

Parte de los no confirmados podrían corresponder a etiologías no estudiadas y explicar algunas diferencias encontradas; sin embargo, también hay importantes similitudes entre los grupos. En ambos, la frecuencia de neumonía $(73,3 \%$ vs $61,5 \%)$ y su presentación radiológica fue muy similar y la edad fue llamativamente menor que los promedios habituales de NAC en años no epidémicos en el HBPM: 41,9 \pm 17,4 y 47,7 \pm 20,3 vs $63 \pm 19$ años ${ }^{9}$. Esto sugiere que al menos parte de nuestros casos hayan sido IA H1N1pdm con RT-PCR (-). Sabemos que independiente del esfuerzo realizado, habrá un grupo de neumonías en las que no se conocerá la etiología. Templeton, buscando etiología de neumonía con RT-PCR, no obtuvo diagnóstico en $24 \%$ y comenta que esto podría mejorar con muestras de esputo o esputo inducido o del tracto respiratorio inferior y no por aspirado nasofaríngeo. Además, las muestras congeladas y descongeladas pueden reducir la sensibilidad de la PCR. Coincidentemente, en el mismo estudio de Templeton, aquellos casos sin diagnóstico eran un grupo oligosintomático, lo que pudiera estar asociado a menor carga viral y menor rendimiento de test diagnósticos ${ }^{10}$. Esto se asemeja a nuestros pacientes con RT-PCR (-) ya que en ellos se identificaron algunos elementos que sugieren formas más leves: hospitalización más breve, ausencia de SDRA, menor requerimiento de UCI y VM. En algunos casos, las muestras se mantuvieron refrigeradas 24 a 48 horas, lo que sumado al traslado a Santiago (24 horas), pudo afectar el rendimiento de la RT-PCR. Basados en estos aspectos, pensamos que pudiéramos estar viendo, al menos en algunos casos no confirmados, expresiones clínicas distintas de la misma enfermedad. Apoya esta hipótesis la menor edad de ambos grupos. Los ancianos tienen mayor probabilidad de tener inmunidad parcial para H1N1pdm por contactos previos y esto explicar la relativa mayor prevalencia del virus en jóvenes. La estratificación por edad en estudios de seroprevalencia sugiere que para IA H1N1pdm, aquellas personas $\geq 60$ años tienen mayor posibilidad de tener anticuerpos neutralizantes ${ }^{11}$.

La neumonía por IA H1N1pdm puede variar de formas leves autolimitadas hasta formas severas con falla respiratoria grave. La descripción clásica de Louria para neumonía después de la pandemia
H2N2 de 1957, señala cuatro categorías: neumonía sin compromiso radiológico, infección viral seguida de neumonía bacteriana, neumonía viral rápidamente progresiva y la concomitancia de neumonía bacteriana y viral ${ }^{12}$.

Creemos que la expresión clínica de la NAC en los casos RT-PCR $(+)$ corresponde principalmente a una neumonía viral primaria, mientras que aquellas no demostradas podrían corresponder a una forma mixta viral-bacteriana de etiología no demostrada. Esto puede verse en parte apoyado por una expresión inflamatoria distinta evidenciada en la respuesta leucocitaria.

En conclusión, nuestro trabajo muestra las dificultades presentadas en un hospital público en el sur de Chile para enfrentar la pandemia de IA H1N1pdm. Hubo que reorganizar y focalizar los recursos físicos, farmacológicos y humanos disponibles lo que determinó, a nuestro juicio, un manejo adecuado de la emergencia. La visita precoz por especialistas en enfermedades respiratorias permitió racionalizar el uso de antibióticos y el control garantizado, facilitó un alta precoz segura. El traslado aéreo de pacientes muy graves con nulo rendimiento nos hace plantear que costos de esa magnitud deberían focalizarse a aumentar la capacidad de resolución de los principales centros hospitalarios del país.

Aquellos pacientes con ETI e IFD(-) en espera de confirmación por RT- PCR fue el grupo más difícil de manejar al decidir el lugar de hospitalización.

Caracterizamos un grupo que no ha sido mayormente descrito y que se comporta como influenza y requiere hospitalización, pero son RT-PCR (-). Un porcentaje de ellos podrían ser casos de influenza en un contexto de mayor edad o presentación oligosintomática. Sin embargo, este grupo plantea el desafío de encontrar otras etiologías, mediante uso de elementos clínicos y de laboratorio que permitan racionalizar y focalizar los tratamientos.

\section{Referencias}

1. Emergence of a Novel Swine-Origin Influenza A (H1N1) in Humans. Novel Swine-Origin Influenza A (H1N1) Virus Investigation Team. N Engl J Med 2009; 360: 25 2605-15.

2. World Health Organization. Transcript of statement by Margaret Chan, Director General of the World Health 
Organization. 2009 Jun 11. [Cited 2009 Oct 8]; [8 p.]. from:http://www.who.int/mediacentre/influenzaAH1N1_presstranscript_20090611.pdf

3. Fang G, Fine M, Orloff J, Arisumi D, Yu V, Kapoor W, et al. New and emerging etiologies for community acquired pneumonia with implications for therapy: A prospective multicenter study of 359 cases. Medicine 1990; 69: 307-16.

4. Mandell L, Wunderink R, Anzueto A, Bartlett, Campbell G, Dean N, et al. Infectious Diseases Society of America/ American Thoracic Society Consensus Guidelines on the Management of Community-Acquired Pneumonia in Adults. CID 2007; 44 (Suppl 2): 27-72.

5. Riquelme R, Riquelme M, Rioseco ML, Inzunza C, Gómez Y, Contreras C, et al. Characteristics of hospitalized patients with 2009 H1N1 influenza in Chile. Eur Respir J 2010 Feb 25.

6. Cunha B, Thekkel V, Cohan C. H1N1 Influenza: Contact investigation burden because of failure to institute influenza precautions in patients with negative rapid influenza diagnostic test results. Infect Control Hosp Epidemiol 2010; 31: 102-4.

7. Falsey A. Community-Acquired viral pneumonia. Clin
Geriatr Med 2007; 23: 535-52.

8. Govaert TME, Dinant GJ, Aretz K, Knottnerus JA. The predictive value of influenza symptomatology in elderly people. Fam Pract 1998; 15: 16-22.

9. Riquelme R, Riquelme M, Rioseco ML, Gómez V, Gil $\mathrm{R}$, Torres A. Etiología y factores pronósticos de la neumonía adquirida en la comunidad en el adulto hospitalizado, Puerto Montt, Chile. Rev Med Chile 2006; 134: 597-605.

10. Templeton K, Scheltinga S, Van der Eeden W, Graffelman W, Van den Broek P, Claas E. Improved diagnosis of the etiology of community acquired pneumonia with Real-Time Polymerase Chain Reaction. CID 2005; 41: 345-51.

11. Centers for Disease Control and Prevention (CDC). Serum cross-reactive antibody response to a novel influenza A (H1N1) virus after vaccination with seasonal influenza vaccine. MMWR Morb Mortal Wkly Rep 2009; 58: 521-4.

12. Louria DE, Blumenfeld HL, Ellis JT, Kilbourne ED, Rogers DE. Studies on influenza in the pandemics of 1957-1958. II. Pulmonary complications of influenza. J Clin Invest 1959; 2: 135-8. 